\title{
Molecular structure and infrared spectra of the monomeric 3-(methoxy)-1,2-benzisothiazole 1,1-dioxide (methyl pseudosaccharyl ether)
}

\author{
Agnieszka Kaczor ${ }^{\mathrm{a}, \mathrm{b}, *}$, Rui Almeida ${ }^{\mathrm{a}, \mathrm{c}}$, Andrea Gómez-Zavaglia ${ }^{\mathrm{a}, \mathrm{d}}$, \\ Maria de Lurdes S. Cristiano ${ }^{b}$, Rui Fausto ${ }^{a}$ \\ a Department of Chemistry, University of Coimbra, Coimbra P-3004-535, Portugal \\ ${ }^{\mathrm{b}}$ Faculty of Chemistry, Jagiellonian University, Ingardena 3, 30-060 Krakow, Poland \\ ${ }^{\mathrm{c}}$ Department of Chemistry and Biochemistry, F.C.T., and CCMAR, University of Algarve, Campus de Gambelas, 8005-039 Faro, Portugal \\ ${ }^{\mathrm{d}}$ Faculty of Pharmacy and Biochemistry, University of Buenos Aires, C.P. 1113 Buenos Aires, Argentina
}

Received 27 April 2007; received in revised form 29 May 2007; accepted 1 June 2007

Available online 20 June 2007

\begin{abstract}
The computational description of saccharin (1,2-benzisothiazol-3(2H)-one-1,1-dioxide) and its derivatives is difficult due to the presence of hypervalent $\mathrm{S}=\mathrm{O}$ bonds in their structures. Therefore, in this investigation, the HF, DFT/B3LYP and MP2 methods were used to predict the geometry and the infrared spectrum of the saccharyl derivative 3-(methoxy)-1,2-benzisothiazole 1,1-dioxide (MBID). Their relative predictive capabilities were then evaluated by comparing the obtained results with experimentally available data, namely the newly obtained IR spectra of MBID isolated in low-temperature inert matrices. For each method, different basis sets $[6-31++\mathrm{G}(\mathrm{d}, \mathrm{p})$, 6-31++G(3df,3pd), 6-311++G(d,p), 6-311++G(2df,2pd), 6-311++G(3df,3pd), aug-cc-pVDZ and aug-cc-pVTZ] were considered. The best overall agreement has been achieved at the B3LYP/6-311++G(3df,3pd) and B3LYP/6-31++G(3df,3pd) levels of theory, showing the adequacy of the B3LYP functional to describe the investigated properties in this type of compounds and stressing the relevance of including high-order polarization functions in the basis set.

The chosen level of theory [B3LYP/6-311++G(3df,3pd)] was applied to analyze the vibrational spectra and the geometry of the title molecule. In agreement with the experiment, the $\mathrm{C}-\mathrm{O}-\mathrm{C}$ linkage in MBID is predicted by these calculations to exhibit considerably short $(1.320 \AA)$ and long $(1.442 \AA)(\mathrm{N}=) \mathrm{C}-\mathrm{O}$ and $\left(\mathrm{H}_{3}\right) \mathrm{C}-\mathrm{O}$ bonds, respectively, and a hybridization of the central oxygen atom close to $\mathrm{sp}^{2}$ (the $\mathrm{C}-\mathrm{O}-\mathrm{C}$ angle is predicted to be $c a .117^{\circ}$ ). This $\mathrm{C}-\mathrm{O}-\mathrm{C}$ bonding pattern fits the well-known high reactivity of $\mathrm{MBID}$ upon thermal rearrangement, which has been shown to result in easy selective $\left[1,3^{\prime}\right]$-isomerization of the compound.
\end{abstract}

(c) 2007 Elsevier B.V. All rights reserved.

Keywords: Methyl pseudosaccharyl ether; Molecular structure; IR spectra; Matrix isolation; DFT and ab initio calculations

\section{Introduction}

Saccharin (1,2-benzisothiazol-3(2H)-one-1,1-dioxide) is a commonly known substance, as it is the oldest artificial sweetener. Apart from the wide commercial applications of saccharin itself, its derivatives receive an increased

\footnotetext{
* Corresponding author. Address: Faculty of Chemistry, Jagiellonian University, Ingardena 3, 30-060 Krakow, Poland.

E-mail address: kaczor@chemia.uj.edu.pl (A. Kaczor).
}

attention as they show herbicidal [1,2], antimicrobial and antifungal activity [3-5] or potential in enzymatic inhibition [6]. Additionally, substituted 1,2-benzisothiazole 1,1dioxides (pseudosaccharins) are important intermediates in the organic synthesis, as their $O$-ethers provide efficient intermediates for reductive cleavage of the $\mathrm{C}-\mathrm{O}$ bond in phenols [7,8], benzylic [9] and naphthylmethylic alcohols [10], through heterogeneous catalytic transfer hydrogenolysis, or through cross-coupling with organometalic reagents [11-13]. Though the presence of $\pi$-type orbitals in the 
substituent is an additional requirement, ensuring a proper alignment of the compound on a catalyst surface (alkylpseudosaccharyl ethers are unreactive) [8], the structural basis of the enhanced reactivity of this kind of pseudosaccharyl ethers towards transition metal-catalyzed ipso-replacement lies in the unusual bond lengths and geometry of their $\mathrm{C}_{\mathrm{R}}-\mathrm{O}-\mathrm{C}_{\mathrm{A}}$ linkage (where $\mathrm{R}=$ heteroaromatic ring and $\mathrm{A}=$ aliphatic or aryl group) $[8-10,13-18]$. The strong electron withdrawing effect of the pseudosaccharyl group results in significant lengthening of the $\mathrm{C}_{\mathrm{A}}-\mathrm{O}$ bond at the expense of the $\mathrm{C}_{\mathrm{R}}-\mathrm{O}$ bond, which then gains partial double-bond character $[8-10,13,19]$. This characteristic structural feature, which is directly related with the potential of the pseudosaccharyl-oxygen system as nucleofuge in TM-catalyzed reductive cleavage, makes pseudosaccharins interesting compounds for structural analysis.

Nowadays, quantum-chemical methods provide powerful support for experimental structural studies. Therefore, both geometry and vibrational properties of saccharin and several metal saccharinates have been extensively studied by ab initio and DFT methods [20-25]. The key problem in these investigations is the difficulty to obtain an accurate description of the $\mathrm{S}=\mathrm{O}$ bond. Indeed, most of the standard computational methods and basis sets have been shown to be unable to properly treat this moiety, leading to considerable discrepancies between the experimental and theoretically predicted values for the $\mathrm{S}=\mathrm{O}$ bond lengths and for the vibrational frequencies associated with this bond [22-25]. The underestimation of the theoretically predicted frequencies for the $\mathrm{S}=\mathrm{O}$ stretching vibrations was noticed previously for different types of compounds containing the $\mathrm{S}=\mathrm{O}$ bond, from simple molecules, as dimethyl sulfate [26], dimethyl sulfite [27] or the $\mathrm{SSO}^{-}$ anion [28], to more complex species, like 5-methyl$1 H, 3 H$-pyrrolo[1,2c][1,3]thiazole-6,7-dicarboxylate 2,2dioxide [29]. Although a good agreement of the experimental and predicted frequencies was achieved for both dimethyl sulfate and sulfite when the B3LYP method was used together with the split valence quadruple- $\zeta$ basis set (aug-cc-pVQZ) [26,27], calculations on pseudosaccharins at this level of theory are currently unpractical due to its excessive computational cost.

In the present investigation, a comprehensive evaluation of commonly used theoretical methods (HF, B3LYP and MP2) with various split valence double and triple- $\zeta$ basis sets was carried out for 3-(methoxy)-1,2-benzisothiazole 1,1-dioxide (MBID), in order to find a suitable and costeffective level of theory to be used in the study of saccharin derivatives. MBID was chosen due to its conformational simplicity (it possesses a single conformer with practical significance). The choice of the target compound was also motivated by our interest to subsequently address the problem of $\left[1,3^{\prime}\right]$-isomerization in pseudosaccharin $O$-ethers, MBID being one of the simplest compounds prone to undergo this type of rearrangement. The experimental method selected to evaluate the computational results was infrared spectroscopy in low-temperature inert matrices. This method allowed obtaining, for the first time, well-resolved pure vibrational spectra of the isolated MBID, which can be directly compared with the theoretical results obtained for the molecule in vacuum, due to the very weak interactions between the medium (noble gas) and the target molecule.

\section{Methods}

\subsection{Experimental}

MBID was synthesized from 3-chloro-1,2-benzisothiazole-1,1-dioxide (pseudosaccharyl chloride), through solvolysis. The saccharyl halide $(0.105 \mathrm{~g}, 5.2 \mathrm{mmol})$ was dissolved in anhydrous methanol $(10 \mathrm{~mL})$ and the mixture was stirred under nitrogen, at room temperature, until TLC analysis (DCM as eluent) indicated the absence of pseudosaccharyl chloride $(10 \mathrm{~min})$. A white precipitate was formed upon stirring. The reaction mixture was diluted with water $(10 \mathrm{~mL})$ and the excess of methanol was removed under reduced pressure. The organic product was then extracted with ethyl acetate $(3 \times 20 \mathrm{~mL})$ and the organic extract washed with aqueous $\mathrm{HCl}(\mathrm{pH} 2-3)$, later with aqueous sodium bicarbonate $(\mathrm{pH} 11-12)$ and finally with water. The organic solution was finally dried over anhydrous sodium sulfate, filtered, and the filtrate evaporated to dryness, under reduced pressure, to give a colourless solid. Recrystallization from toluene gave the required product, 3-methoxy-1,2-benzisothiazol-1,1-dioxide as colourless crystals $\left(62 \%\right.$ yield; m.p. $\left.184-185^{\circ} \mathrm{C}\right)$.

${ }^{1} \mathrm{H}$ NMR $\left(300 \mathrm{MHz}, \mathrm{CDCl}_{3}\right): \delta, 3.39(3 \mathrm{H}, \mathrm{s}), 7.40(1 \mathrm{H}$, t), 7.89-8.02 (3H, m) MS (EI): $m / z$ 181([M $\left.]^{+}, 100\right)$.

The infrared spectra were recorded in the 400 $4000 \mathrm{~cm}^{-1}$ range using a Mattson Infinity 60AR series FT-IR spectrometer, with $0.5 \mathrm{~cm}^{-1}$ resolution. The sample was co-deposited with argon (N60, Air Liquide) or krypton (N48, Air Liquide) isolant gas onto a cryogenically cooled CsI window. The compound was sublimated at $c a$. 330 $351 \mathrm{~K}$ from a specially designed mini-furnace assembled inside the cryostat. The selected temperature of the optical substrate $(10 \mathrm{~K})$ was obtained using an APD Cryogenics closed-cycle helium refrigeration system with a DE-202A expander. The temperature was measured directly at the sample holder by a silicon diode temperature sensor, connected to a digital controller (Scientific Instruments, Model 9650-1) with the accuracy of $0.1 \mathrm{~K}$.

\subsection{Computational}

Geometry optimizations were performed at the HF, DFT (B3LYP [30,31]) and MP2 levels of theory, using the $6-31++G(d, p)$ and $6-311++G(d, p)$ basis sets for $\mathrm{MP} 2$, the $6-31++\mathrm{G}(\mathrm{d}, \mathrm{p}), \quad 6-311++\mathrm{G}(\mathrm{d}, \mathrm{p})$ and 6$311++\mathrm{G}(3 \mathrm{df}, 3 \mathrm{pd})$ basis sets for HF and all these basis sets plus the $6-31++\mathrm{G}(3 \mathrm{df}, 3 \mathrm{pd}), 6-311++\mathrm{G}(2 \mathrm{df}, 2 \mathrm{pd})$, aug-ccpVDZ and aug-cc-pVTZ bases for B3LYP. In some cases, the Geometry Direct Inversion of the Invariant Subspace 
(GDIIS) method of optimization [32,33] was applied. Vibrational frequencies were calculated at each level of theory and the nature of the stationary points on the potential energy surface (PES) resulting from optimization was determined by inspection of the corresponding calculated Hessian matrix. The optimized structures described in this study were confirmed to correspond to true minimum energy conformations on the different potential energy surfaces investigated.

Potential energy profile for internal rotation was calculated performing a relaxed scan on the DFT (B3LYP)/6$311++\mathrm{G}(3 \mathrm{df}, 3 \mathrm{pd}) \quad$ PES along the relevant reaction coordinate.

All the above-mentioned calculations were performed using the Gaussian98 [34] or Gaussian03 [35] suites of programs. Potential energy distributions (PEDs) of the normal modes were computed in terms of natural internal coordinates [36] with the Gar2ped [37] program.

\section{Results and discussion}

\subsection{Conformational distribution in $M B I D$}

The $\mathrm{N}_{8}=\mathrm{C}_{9}-\mathrm{O}_{15}-\mathrm{C}_{17}$ dihedral angle is the only relevant coordinate for conformational flexibility within the MBID molecule (see Fig. 1). The potential energy profile for internal rotation around the $\mathrm{C}_{9}-\mathrm{O}_{15}$ bond, calculated at the $\mathrm{B} 3 \mathrm{LYP} / 6-311++\mathrm{G}(3 \mathrm{df}, 3 \mathrm{pd})$ level, is given in Fig. 2. In the global minimum conformation, the $\mathrm{N}_{8}=\mathrm{C}_{9}-\mathrm{O}_{15}-\mathrm{C}_{17}$ dihedral angle is $0^{\circ}$ and the molecule exhibits $\mathrm{C}_{\mathrm{s}}$ symmetry. The energy is computed to increase quite steeply until the $\mathrm{N}_{8}=\mathrm{C}_{9}-\mathrm{O}_{15}-\mathrm{C}_{17}$ angle is $\pm 120^{\circ}$; from this point on, a nearly flat profile is predicted, exhibiting a very shallow minimum at $\pm 180^{\circ}$. The less stable conformer is $c a .47 \mathrm{~kJ} \mathrm{~mol}^{-1}$ higher in energy than the conformational ground state.

Taking into account the large energy difference between the two MBID conformers, it can confidently be stated that, in the range of temperatures used to sublime the compound for matrix preparation ( $c a .330-351 \mathrm{~K}$ ), the higher energy form is of no practical importance due to its exceedingly small population. This form will then be neglected from now on.

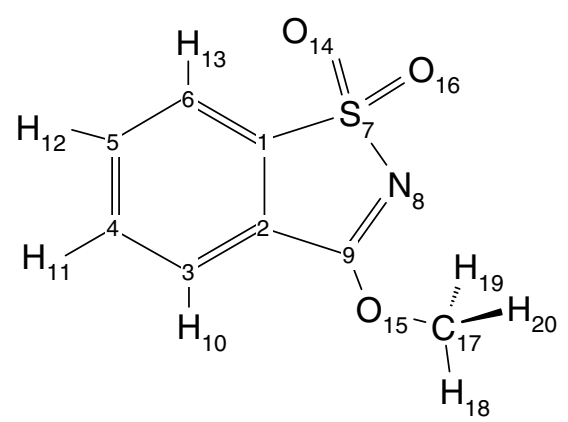

Fig. 1. Adopted atom numbering scheme for the MBID molecule. Ring carbon atoms are only represented by their numbers.

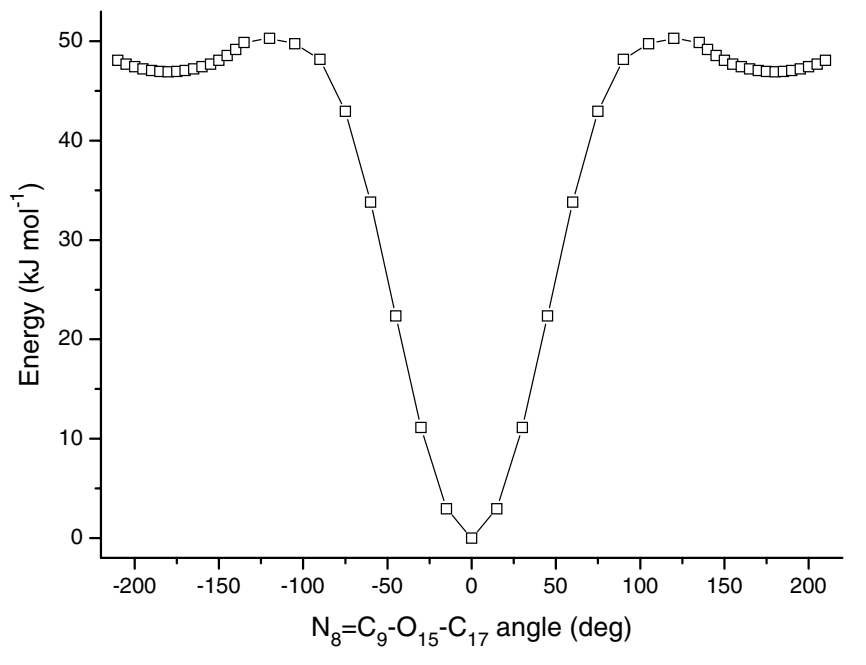

Fig. 2. Potential energy profile for internal rotation around the $\mathrm{N}_{8}=\mathrm{C}_{9}-\mathrm{O}_{15}-\mathrm{C}_{17}$ dihedral angle, calculated at the B3LYP/6$311++\mathrm{G}(3 \mathrm{df}, 3 \mathrm{pd})$ level of theory.

\subsection{Vibrational spectra of $M B I D$ and evaluation of computational methods}

The infrared spectra of MBID isolated in solid argon and krypton at $10 \mathrm{~K}$ are given in Fig. 3 along with the theoretical spectra of the most stable monomer calculated at different levels of theory. Computed frequencies have been scaled down to account for anharmonicity and limitations of the basis sets. The scaling factors were found by linear fitting of a criteriously chosen set of well-defined experimental (argon) and calculated frequencies (given in Table S1 of the Supplementary Material), with the intercept of the line set on zero. The scaling factors used in the present analysis are given in Table 1, which also includes the frequencies of the bands attributed to the $\mathrm{S}=\mathrm{O}$ asymmetric and symmetric stretching vibrations. Definition of the internal coordinates used in the normal mode analysis of MBID and computed B3LYP/6-311++G(3df,3pd) frequencies and IR intensities are given in Tables S2 and S3. The assignments for the matrix spectra are provided in Table 2.

The comparison of the computed vibrational frequencies with the matrix data enabled unequivocal evaluation of the applied methods. As it will be shown below, the B3LYP/6-311++G(3df,3pd) calculations give the best overall agreement between theoretically predicted and observed spectral features, and then, among the different alternatives tested, appear as the most convenient theoretical approach to the study of the type of compounds under consideration.

The most striking differences between the experimental and calculated spectra occur for the absorptions associated with the $\mathrm{S}=\mathrm{O}$ stretching vibrations. For these vibrations, a considerable discrepancy can be noticed for all the levels of theory tested, apart from $\mathrm{HF} / 6-311++\mathrm{G}(3 \mathrm{df}, 3 \mathrm{pd})$, B3LYP/6-31++G(3df,3pd) and B3LYP/6-311++G(3df, $3 \mathrm{pd})$. Note, however, that although surprisingly good 


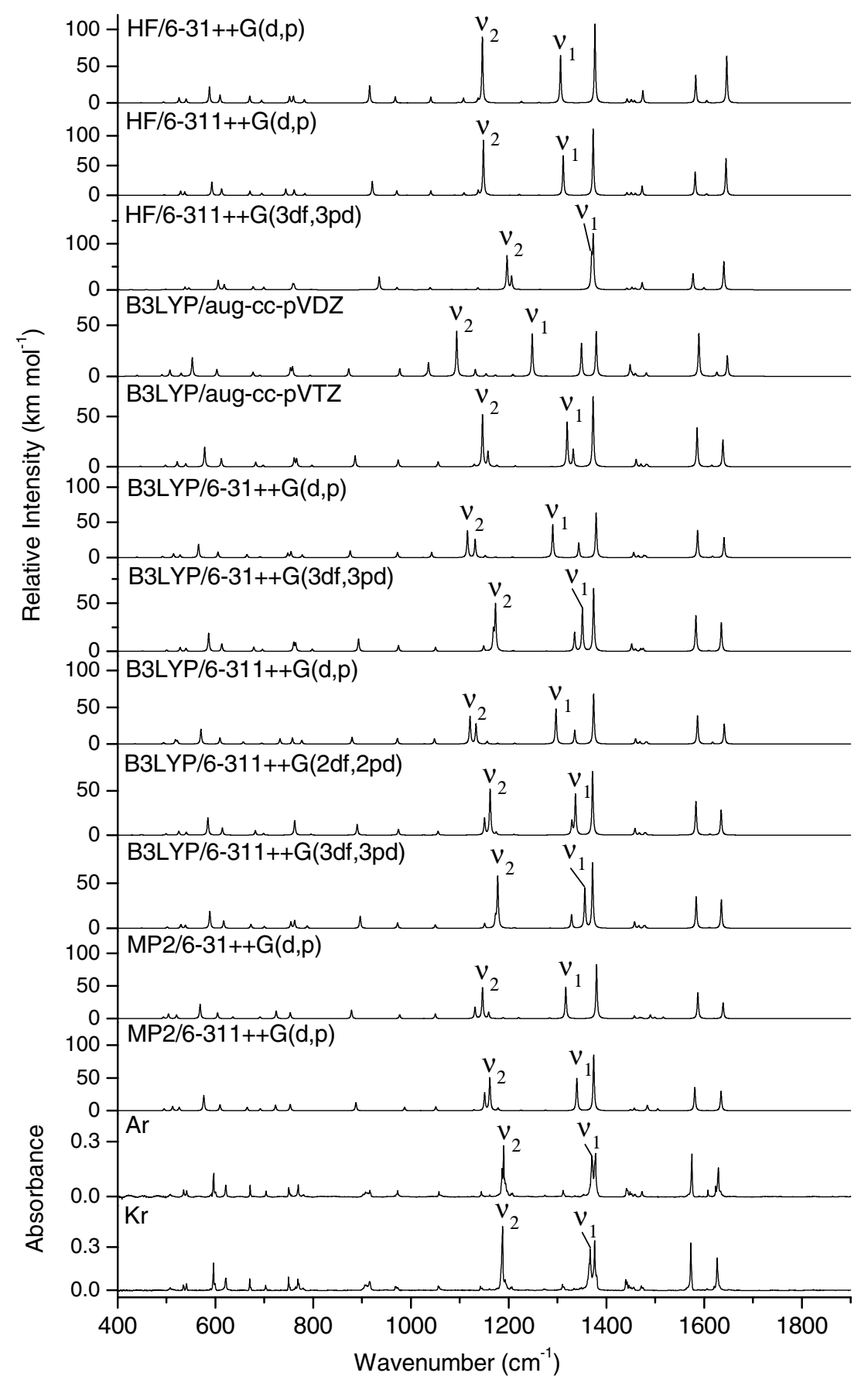

Fig. 3. Comparison of the FT-IR spectra of monomeric MBID isolated in argon and krypton matrices with the theoretical spectra obtained at different levels of theory. $v_{1}$ and $v_{2}$ denote the bands associated mainly with the asymmetric and symmetric $\mathrm{S}=\mathrm{O}$ stretching vibrations, respectively.

estimations for the $\mathrm{S}=\mathrm{O}$ stretching frequencies were obtained at the $\mathrm{HF} / 6-311++\mathrm{G}(3 \mathrm{df}, 3 \mathrm{pd})$ level, considerable disagreement with the experimental data was observed for both frequencies and intensities of other absorptions, disapproving the use of this method. For example, the description of the relative intensities of the bands in the $1650-1400 \mathrm{~cm}^{-1}$ region is erroneous, with the relative intensities of the two intense bands attributed mainly to the $\mathrm{C}=\mathrm{N}$ bond stretching coordinate being reversed at the HF level (whatever the basis set used; see Fig. 3). The frequency separation between these two bands is also overestimated by the HF method $\left(63 \mathrm{~cm}^{-1}\right.$ for all basis sets) relative to experiment $\left(54 \mathrm{~cm}^{-1}\right.$ for both $\mathrm{Ar}$ and $\mathrm{Kr}$ ) and all other methods applied $\left(51-55 \mathrm{~cm}^{-1}\right.$, with the exception of B3LYP/aug-cc-pVDZ, for which it is $58 \mathrm{~cm}^{-1}$ ).

In the experiment, the absorption due to the asymmetric $\mathrm{S}=\mathrm{O}$ stretching mode is observed at $1370 \mathrm{~cm}^{-1}$ in argon and at $1367 \mathrm{~cm}^{-1}$ in krypton, whereas that corresponding to the symmetric $\mathrm{S}=\mathrm{O}$ stretching is found at $1189 \mathrm{~cm}^{-1}$ (Ar) and at $1188 \mathrm{~cm}^{-1}(\mathrm{Kr})$. An error of 
Table 1

Comparison of frequencies of the $\mathrm{S}=\mathrm{O}$ stretching vibrations calculated at different levels of theory with the experimental values

\begin{tabular}{|c|c|c|c|}
\hline & \multicolumn{2}{|c|}{ Frequency $\left(\mathrm{cm}^{-1}\right)^{\mathrm{a}}$} & \multirow{2}{*}{$\begin{array}{l}\text { Scaling } \\
\text { factor }^{\mathrm{b}}\end{array}$} \\
\hline & $\begin{array}{l}v(\mathrm{~S}=\mathrm{O}) \\
\text { asymmetric }\end{array}$ & $\begin{array}{l}v(\mathrm{~S}=\mathrm{O}) \\
\text { symmetric }\end{array}$ & \\
\hline \multicolumn{4}{|l|}{ Experimental } \\
\hline Argon matrix & 1370 & 1189 & \\
\hline Krypton matrix & 1367 & 1188 & \\
\hline \multicolumn{4}{|l|}{ Calculated } \\
\hline $\mathrm{HF} / 6-31++\mathrm{G}(\mathrm{d}, \mathrm{p})$ & $1306(4.6)$ & $1146(3.6)$ & 0.897 \\
\hline $\mathrm{HF} / 6-311++\mathrm{G}(\mathrm{d}, \mathrm{p})$ & $1311(4.2)$ & $1148(3.4)$ & 0.901 \\
\hline $\mathrm{HF} / 6-311++\mathrm{G}(3 \mathrm{df}, 3 \mathrm{pd})$ & $1370(0.1)$ & $1197(0.7)$ & 0.901 \\
\hline B3LYP/aug-cc-pVDZ & $1248(8.8)$ & $1093(8.0)$ & 0.995 \\
\hline B3LYP/aug-cc-pVTZ & $1319(3.6)$ & $1146(3.6)$ & 0.990 \\
\hline B3LYP/6-31++G(d,p) & $1290(5.7)$ & $1116(6.1)$ & 0.986 \\
\hline B3LYP/6-31++G(3df,3pd) & $1351(1.3)$ & $1173(1.3)$ & 0.988 \\
\hline B3LYP/6-311++G(d,p) & $1296(5.3)$ & $1120(5.7)$ & 0.991 \\
\hline B3LYP/6-311++G(2df,2pd) & $1337(2.3)$ & $1162(2.2)$ & 0.988 \\
\hline B3LYP/6-311++G(3df,3pd) & $1355(1.0)$ & $1177(1.0)$ & 0.987 \\
\hline $\mathrm{MP} 2 / 6-31++\mathrm{G}(\mathrm{d}, \mathrm{p})$ & $1316(3.8)$ & $1146(3.6)$ & 0.984 \\
\hline $\mathrm{MP} 2 / 6-311++\mathrm{G}(\mathrm{d}, \mathrm{p})$ & $1339(2.2)$ & $1161(2.3)$ & 0.991 \\
\hline
\end{tabular}

a The percent error relative to the averaged experimental (argon and krypton) results is given in the parentheses.

${ }^{\mathrm{b}}$ Scaling factors were found by linear fitting (assuming a zero intercept) of the chosen set of experimental and calculated frequencies (for details refer to the text).

$1.0 \%$ relative to the averaged (argon and krypton) experimental frequencies was obtained for both $\mathrm{S}=\mathrm{O}$ stretching frequencies calculated at the B3LYP/6$311++\mathrm{G}(3 \mathrm{df}, 3 \mathrm{pd})$ level (see Table 1). Compared to these results, the error doubled when the significantly more time-consuming MP2/6-311++G(d,p) level of theory was used $\left(2.2 / 2.3 \%\right.$; calc.: $\left.1339 \mathrm{~cm}^{-1}, 1161 \mathrm{~cm}^{-1}\right)$ and it nearly quadrupled for the same method, but with the double- $\zeta$ basis set $\left(3.8 / 3.6 \%\right.$; calc.: $1316 \mathrm{~cm}^{-1}$, $\left.1146 \mathrm{~cm}^{-1}\right)$.

On the other hand, the B3LYP functional used together with the very common and usually efficient $6-31++G(d, p)$ and $6-311++\mathrm{G}(\mathrm{d}, \mathrm{p})$ basis sets gave results that are significantly worse (errors in the range of $5.3-6.1 \%$; calc.: $1290 \mathrm{~cm}^{-1}, 1116 \mathrm{~cm}^{-1}$ and $1296 \mathrm{~cm}^{-1}, 1120 \mathrm{~cm}^{-1}$, for double- $\zeta$ and triple- $\zeta$ basis set, respectively) not only than MP2, but also HF. For the latter, errors were in the range of $3.4-4.6 \%$ (calc.: $1306 \mathrm{~cm}^{-1}, 1146 \mathrm{~cm}^{-1}$ and $1311 \mathrm{~cm}^{-1}$, $1148 \mathrm{~cm}^{-1}$, for double- $\zeta$ and triple- $\zeta$ basis set, respectively). Furthermore, application of this functional with the augcc-pVDZ basis set brought an even higher discrepancy between the experimental and calculated frequencies (8.8/ $8.0 \%$; calc.: $\left.1248 \mathrm{~cm}^{-1}, 1093 \mathrm{~cm}^{-1}\right)$. Using the respective triple- $\zeta$ basis set (aug-cc-pVTZ) instead of the double- $\zeta$ one reduced the error to $3.6 \%$ for both modes (calc.: $\left.1319 \mathrm{~cm}^{-1}, 1146 \mathrm{~cm}^{-1}\right)$. Nevertheless, this error is still much larger than that obtained when the B3LYP/6$311++\mathrm{G}(3 \mathrm{df}, 3 \mathrm{pd})$ level of theory is used.

From the whole set of results, it became evident that the number of polarization functions present in the basis set strongly influences the agreement between the experimental and calculated values. Indeed, both the general performance as well as the theoretical estimation of the $v \mathrm{~S}=\mathrm{O}$ frequencies progressively lose quality when $\mathrm{B} 3 \mathrm{LYP} / 6-311++\mathrm{G}(3 \mathrm{df}, 3 \mathrm{pd})$ is restricted to $\mathrm{B} 3 \mathrm{LYP} / 6-311++\mathrm{G}(2 \mathrm{df}, 2 \mathrm{pd})$ and further to $\mathrm{B} 3 \mathrm{LYP} / 6-$ $311++\mathrm{G}(\mathrm{d}, \mathrm{p})$. This conclusion is also reinforced if one compares the results obtained with the 6$31++\mathrm{G}(3 \mathrm{df}, 3 \mathrm{pd})$ and $6-311++\mathrm{G}(2 \mathrm{df}, 2 \mathrm{pd})$ basis sets used together with the B3LYP functional. The obtained agreement between the experimental and computed $v \mathrm{~S}=\mathrm{O}$ frequencies was definitely better for the double- $\zeta$ basis with the full set of polarization functions (error: 1.3\% for both frequencies; calc.: $1351 \mathrm{~cm}^{-1}, 1173 \mathrm{~cm}^{-1}$ ) than for the triple- $\zeta$ basis set with lower number of polarization functions.

The number of basis functions in the basis set, however, does not significantly influences the results if the same set of polarization functions is used. Vibrational frequencies obtained with the "full" 6-311++G(3df,3pd) basis set are only slightly better than those obtained with the 6$31++\mathrm{G}(3 \mathrm{df}, 3 \mathrm{pd})$ basis. Therefore, the latter is certainly an adequate choice for the theoretical treatment of pseudosaccharins of bigger size.

On the other hand, the choice of the type of the basis set significantly affects the vibrational frequencies. Comparison of B3LYP/6-311++G(2df,2pd) with B3LYP/aug-ccpVTZ (see Fig. 3), both having the same set of polarization functions, clearly shows that the Dunning's correlation consistent basis set performs much worse than the Pople's basis set. This trend is even more evident upon reducing the level of calculation, i.e., when the B3LYP/6-31++G(d,p) vs. the $\mathrm{B} 3 \mathrm{LYP} / \mathrm{aug}-\mathrm{cc}-\mathrm{pVDZ}$ results are compared, with the latter being completely unsuccessful to perform reasonably in the whole considered range of frequencies (see Fig. 3).

A final note must be made regarding use of MP2 calculations. For a given basis set, the MP2 method produces the best description of the vibrational spectra of MBID when compared with both B3LYP and HF. However, at the MP2/6-311++G(d,p) level, the $v \mathrm{~S}=\mathrm{O}$ frequencies are overestimated by $c a .30 \mathrm{~cm}^{-1}$. Much better results are obtained at the much less time-consuming B3LYP/6$311++\mathrm{G}(3 \mathrm{df}, 3 \mathrm{pd})$ level, which yields the $\nu \mathrm{S}=\mathrm{O}$ frequencies overestimated only by $c a .15 \mathrm{~cm}^{-1}$. Therefore, taking into account the time factor, the MP2 was not tested at the higher levels, as the method does not seem practical to the computation of the vibrational spectra of pseudosaccharyl ethers.

\subsection{Geometry of $M B I D$}

As the best agreement between the experimental and computed vibrational frequencies was achieved at the B3LYP/6-311++G(3df,3pd) level of theory, the latter will be here used as the reference method in the analysis of geometry of MBID (see Fig. 4). 
Table 2

Assignment of experimental IR spectra of MBID isolated in an argon and krypton matrices

\begin{tabular}{|c|c|c|c|c|c|c|}
\hline \multicolumn{2}{|c|}{ Calculated values ${ }^{\mathrm{a}} \mathrm{B} 3 \mathrm{LYP} / 6-311++\mathrm{G}(3 \mathrm{df}, 3 \mathrm{pd})$} & \multicolumn{2}{|l|}{$\operatorname{Argon}(10 \mathrm{~K})$} & \multicolumn{2}{|l|}{ Krypton $(10 \mathrm{~K})$} & \multirow[t]{2}{*}{ Approximate assignment } \\
\hline$v / \mathrm{cm}^{-1}$ & $I / \mathrm{km} \mathrm{mol}^{-1}$ & $v / \mathrm{cm}^{-1}$ & $I$ & $v / \mathrm{cm}^{-1}$ & $I$ & \\
\hline 3167 & 5.4 & 3076 & vw & & & $v \mathrm{C}-\mathrm{H}_{6 \mathrm{R}}$ \\
\hline 3164 & 2.2 & & & & & $v \mathrm{C}-\mathrm{H}_{6 \mathrm{R}}$ \\
\hline 3152 & 4.6 & 3049 & & & & $v \mathrm{C}-\mathrm{H}_{6 \mathrm{R}}$ \\
\hline 3139 & 1.2 & & vw & & & $v \mathrm{C}-\mathrm{H}_{6 \mathrm{R}}$ \\
\hline 3127 & 10.3 & & & & & $v \mathrm{C}-\mathrm{H}_{\mathrm{M}}$ \\
\hline 3095 & 8.9 & 3004 & $\mathrm{vw}$ & & & $v \mathrm{C}-\mathrm{H}_{\mathrm{M}}$ \\
\hline 3019 & 24.8 & 2956 & w & 3013 & $\mathrm{w}$ & $v \mathrm{C}-\mathrm{H}_{\mathrm{M}}$ \\
\hline 1634 & 150.4 & $1635^{\mathrm{b}} / 1633 / 1629$ & $\mathrm{~m} / \mathrm{m} / \mathrm{vs}$ & $1632 / 1627$ & $\mathrm{w} / \mathrm{vs}$ & $v \mathrm{C}=\mathrm{N}, v \mathrm{C}-\mathrm{C}_{6 \mathrm{R}}$ \\
\hline 1610 & 3.6 & 1599 & $\mathrm{vw}$ & 1597 & $\mathrm{vw}$ & $v \mathrm{C}-\mathrm{C}_{6 \mathrm{R}}$ \\
\hline 1583 & 164.7 & $1575 / 1568^{\mathrm{b}}$ & $\mathrm{vs} / \mathrm{m}$ & $1568 / 1565^{\mathrm{b}}$ & $\mathrm{vs} / \mathrm{w}$ & $v \mathrm{C}-\mathrm{C}_{6 \mathrm{R}}, v \mathrm{C}=\mathrm{N}$ \\
\hline 1478 & 11.1 & 1479 & $\mathrm{vw}$ & 1475 & w & $\delta \mathrm{C}-\mathrm{C}-\mathrm{H}_{6 \mathrm{R}}$ \\
\hline 1476 & 10.8 & 1473 & $\mathrm{~m}$ & 1472 & $\mathrm{w}$ & $\delta_{\mathrm{M}}$ \\
\hline 1466 & 2.7 & 1459 & $\mathrm{w}$ & 1456 & $\mathrm{w}$ & $\delta_{\mathrm{M}}$ \\
\hline 1465 & 11.3 & 1457 & $\mathrm{w}$ & 1454 & w & $\delta_{\mathrm{M}}$ \\
\hline \multirow[t]{2}{*}{1457} & 33.6 & 1443 & $\mathrm{~m}$ & 1442 & $\mathrm{~m}$ & $\delta_{\mathrm{M}}$ \\
\hline & & 1441 & $\mathrm{~m}$ & 1440 & $\mathrm{~m}$ & $\delta_{\mathrm{M}}$ \\
\hline 1371 & 340.8 & $1383^{\mathrm{b}} / 1378 / 1376^{\mathrm{b}}$ & $\mathrm{w} / \mathrm{vs} / \mathrm{vs}$ & $1380^{\mathrm{b}} / 1376$ & $\mathrm{~m} / \mathrm{vs}$ & $v \mathrm{C}-\mathrm{O}, v \mathrm{C}-\mathrm{C}_{5 \mathrm{R}}$ \\
\hline \multirow[t]{6}{*}{1355} & 210.6 & $1370 / 1368^{\mathrm{b}} / 1366^{\mathrm{b}}$ & $\mathrm{vs} / \mathrm{vs} / \mathrm{w}$ & $1367 / 1365^{\mathrm{b}} / 1361^{\mathrm{b}}$ & $\mathrm{vs} / \mathrm{w} / \mathrm{w}$ & $v \mathrm{~S}=\mathrm{O}$ \\
\hline & & $1355 / 1354$ & $\mathrm{w} / \mathrm{w}$ & 1354 & $\mathrm{w}$ & \\
\hline & & & & $1349 / 1347$ & $\mathrm{w} / \mathrm{w}$ & \\
\hline & & 1342 & $\mathrm{w}$ & 1340 & w & \\
\hline & & 1336 & $\mathrm{w}$ & 1334 & $\mathrm{w}$ & \\
\hline & & 1322 & $\mathrm{w}$ & 1321 & $\mathrm{w}$ & \\
\hline 1328 & 70.8 & $1315^{\mathrm{b}} / 1313^{\mathrm{b}} / 1312$ & $\mathrm{w} / \mathrm{w} / \mathrm{m}$ & $1313^{\mathrm{b}} / 1310$ & $\mathrm{w} / \mathrm{m}$ & $v \mathrm{C}-\mathrm{C}_{6 \mathrm{R}}$ \\
\hline \multirow[t]{2}{*}{1284} & 1.5 & $1277^{b} / 1274$ & $\mathrm{wv} / \mathrm{wv}$ & $1275 / 1273 / 1272$ & $\mathrm{wv} / \mathrm{wv} / \mathrm{wv}$ & $\delta \mathrm{C}-\mathrm{C}-\mathrm{H}_{6 \mathrm{R}}$ \\
\hline & & $1242^{\mathrm{b}} / 1239$ & wv/wv & $1243^{\mathrm{b}} / 1240^{\mathrm{b}} / 1237$ & $\mathrm{wv} / \mathrm{wv} / \mathrm{wv}$ & \\
\hline \multirow[t]{2}{*}{1211} & 3.6 & 1208 & $\mathrm{w}$ & 1206 & $\mathrm{w}$ & $\delta_{\mathrm{M}}$ \\
\hline & & 1205 & $\mathrm{w}$ & 1204 & w & $\delta_{\mathrm{M}}$ \\
\hline 1177 & 270.7 & 1199/1197/1194/1192/1190 & $\mathrm{w} / \mathrm{m} / \mathrm{m} / \mathrm{m} / \mathrm{vs}$ & 1193 & vs & $v \mathrm{~S}=\mathrm{O}$ \\
\hline 1172 & 52.9 & $1187 / 1185$ & $\mathrm{~s} / \mathrm{m}$ & $1187^{\mathrm{b}}$ & $\mathrm{m}$ & $\delta \mathrm{C}-\mathrm{C}-\mathrm{H}_{6 \mathrm{R}}$ \\
\hline 1160 & 0.9 & 1161 & $\mathrm{vw}$ & 1160 & wv & $\delta_{\mathrm{M}}$ \\
\hline 1150 & 25.1 & $1148 / 1144$ & $\mathrm{~m} / \mathrm{m}$ & $1146 / 1142$ & $\mathrm{~m} / \mathrm{m}$ & $\delta \mathrm{C}-\mathrm{C}-\mathrm{H}_{6 \mathrm{R}}, v \mathrm{C}-\mathrm{C}_{6 \mathrm{R}}$ \\
\hline 1129 & 0.2 & & & & & $\delta \mathrm{C}-\mathrm{C}-\mathrm{H}_{6 \mathrm{R}}, v \mathrm{C}-\mathrm{C}_{6 \mathrm{R}}$ \\
\hline 1049 & 18.9 & $1061^{\mathrm{b}} / 1057$ & $\mathrm{w} / \mathrm{m}$ & $1062^{\mathrm{b}} / 1058 / 1056$ & $\mathrm{vw} / \mathrm{m} / \mathrm{m}$ & $\delta \mathrm{C}-\mathrm{C}-\mathrm{C}_{6 \mathrm{R}}$ \\
\hline 1025 & 0.9 & 1017 & $\mathrm{vw}$ & 1017 & $\mathrm{vw}$ & $v \mathrm{C}-\mathrm{C}_{6 \mathrm{R}}$ \\
\hline 1005 & 0.0 & & & & & $\gamma_{6 \mathrm{R}}$ \\
\hline 972 & 29.1 & 973/970/966 & $\mathrm{m} / \mathrm{w} / \mathrm{w}$ & 974/973/970/968 & $\mathrm{m} / \mathrm{m} / \mathrm{m} / \mathrm{m}$ & $v \mathrm{C}_{17}-\mathrm{O}$ \\
\hline 970 & 0.6 & & & & & $\gamma_{6 \mathrm{R}}, \gamma_{5 \mathrm{R}}$ \\
\hline 896 & 63.5 & $917^{\mathrm{b}} / 916 / 913 / 911 / 910 / 907 / 903$ & $\mathrm{~m} / \mathrm{m} / \mathrm{m} / \mathrm{m} / \mathrm{m} / \mathrm{m}$ & 915/908/906 & $\mathrm{m} / \mathrm{m} / \mathrm{m}$ & $v \mathrm{~N}-\mathrm{S}, \delta \mathrm{X}-\mathrm{C}-\mathrm{O}$ \\
\hline 891 & 0.0 & & & & & $\gamma_{6 \mathrm{R}}$ \\
\hline 787 & 13.6 & 780/779/771/770 & $\mathrm{w} / \mathrm{w} / \mathrm{w} / \mathrm{m}$ & $783^{\mathrm{b}} / 780 / 771 /$ & $\mathrm{w} / \mathrm{w} / \mathrm{m}$ & \\
\hline 762 & 41.3 & $768^{b} / 765$ & $\mathrm{~m} / \mathrm{w}$ & $768 / 764 / 762$ & $\mathrm{~m} / \mathrm{w} / \mathrm{w}$ & $\delta \mathrm{C}-\mathrm{C}-\mathrm{C}_{6 \mathrm{R}}$ \\
\hline 754 & 32.3 & $756 / 753 / 751^{\mathrm{b}} / 750$ & $\mathrm{w} / \mathrm{w} / \mathrm{m} / \mathrm{m}$ & $752 / 751^{\mathrm{b}} / 750$ & $\mathrm{w} / \mathrm{m} / \mathrm{m}$ & $\gamma_{6 \mathrm{R}}, \tau_{6 \mathrm{R}}$ \\
\hline 700 & 10.2 & 704 & $\mathrm{~m}$ & $705^{\mathrm{b}} / 703$ & $\mathrm{~m} / \mathrm{w}$ & $\delta \mathrm{C}-\mathrm{C}-\mathrm{C}_{6 \mathrm{R}}$ \\
\hline 672 & 20.8 & $673^{\mathrm{b}} / 671$ & $\mathrm{w} / \mathrm{m}$ & $673^{\mathrm{b}} / 972^{\mathrm{b}} / 670$ & $\mathrm{w} / \mathrm{w} / \mathrm{m}$ & \\
\hline 617 & 39.4 & 621 & $\mathrm{~m}$ & 621 & $\mathrm{~m}$ & $\delta \mathrm{C}-\mathrm{C}-\mathrm{C}_{6 \mathrm{R}}, \delta \mathrm{X}-\mathrm{S}=\mathrm{O}$ \\
\hline 588 & 90.0 & $600 / 597 / 596 / 592$ & $\mathrm{w} / \mathrm{s} / \mathrm{s} / \mathrm{vw}$ & $599 / 596 / 590 / 589^{\mathrm{b}}$ & $\mathrm{w} / \mathrm{s} / \mathrm{vw} / \mathrm{vw}$ & $\gamma \mathrm{C}-\mathrm{S}(=\mathrm{O})-\mathrm{N}, \delta \mathrm{C}-\mathrm{X}-\mathrm{X}_{5 \mathrm{R}}$ \\
\hline 538 & 15.5 & 542 & $\mathrm{~m}$ & 540 & $\mathrm{~m}$ & $\gamma \mathrm{C}-\mathrm{S}(=\mathrm{O})-\mathrm{N}, \delta \mathrm{C}-\mathrm{X}-\mathrm{X}_{5 \mathrm{R}}, \tau_{6 \mathrm{R}}$ \\
\hline 529 & 20.1 & 535 & $\mathrm{w}$ & $536^{\mathrm{b}} / 543$ & $\mathrm{~m} / \mathrm{m}$ & $\delta \mathrm{X}-\mathrm{S}=\mathrm{O}$ \\
\hline 501 & 7.5 & 507 & $\mathrm{w}$ & 507 & $\mathrm{w}$ & $\delta \mathrm{C}-\mathrm{X}-\mathrm{X}_{5 \mathrm{R}}$ \\
\hline
\end{tabular}

Frequencies scaled uniformly by the factor of 0.987 .

b Shoulder. 
The computed values of bond angles and dihedral angles are practically coincident for all methods used, the major differences being $3.5^{\circ}$ and $1.3^{\circ}$, respectively. Also the calculated values of the bond lengths are considerably conserved throughout the molecule (major difference $\leqslant 0.02 \AA$ ) with the exception of the bonds linking the substituent to the saccharin moiety (both $\mathrm{C}-\mathrm{O}$ bonds) and, specially, the bonds involving the sulfur atom, for which considerable deviations are noticed (see Table 3).

The bonding description of formally hypervalent molecules requires inclusion of both electron correlation and polarization functions [38]. The crucial importance of polarization functions, particularly of the f-type was also previously emphasized in studies of the relative energies of sulfur-containing molecules of the $\mathrm{C}_{2} \mathrm{~S}_{2} \mathrm{H}_{2}$ type $[39,40]$. The interesting conclusion presented by Vijay et al. was the apparent inadequacy of DFT methods to predict relative energies of the $\mathrm{C}_{2} \mathrm{~S}_{2} \mathrm{H}_{2}$ isomers [40]. On the other hand, the present study supports the adequacy of the DFT approach to study sulfur compounds once the proper basis set and functional has been chosen (although it has to be underlined that we did not consider specifically relative conformational energies, due to the fact that MBID has only one experimentally meaningful conformer, but the relative performances of several theoretical methods to calculate accurate vibrational frequencies.) This apparent discrepancy might be rationalized if we take into consideration the different basis sets applied by Vijay et al. $\left(6-31 G^{*}, 6-311 G^{*}, 6-\right.$ $311+\mathrm{G}^{*}, \quad 6-311+\mathrm{G}^{* *}, \quad 6-311++\mathrm{G}^{* *}, \quad 6-31 \mathrm{G}(2 \mathrm{df}), \quad 6-$ $31 \mathrm{G}(3 \mathrm{df}), 6-31 \mathrm{G}(3 \mathrm{df}, 3 \mathrm{pd})[40])$ and in the present work or the dissimilarity of the systems under study.

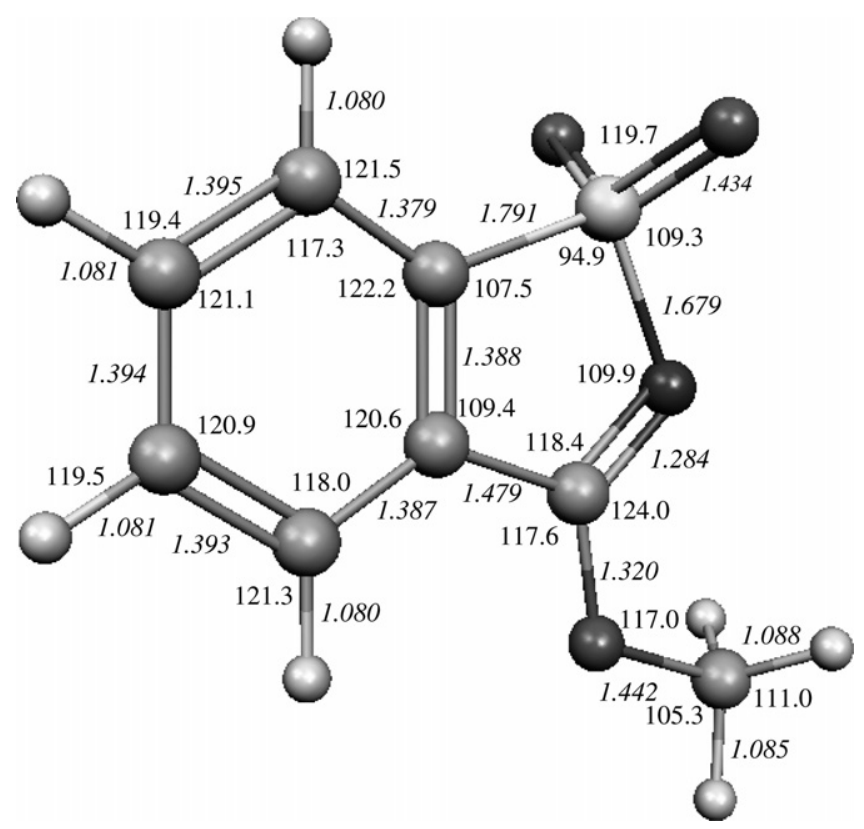

Fig. 4. The B3LYP/6-311++G(3df,3pd) optimized geometry of MBID. Values of bond lengths (in italics, $\AA$ ) and valence angles (degrees) are given.
In the thorough study of the $\mathrm{C}_{2} \mathrm{~S}_{2} \mathrm{H}_{2}$ isomers, the authors stated also that the HF method reproduces the energy trend, but they ascribed it to incidental cancellation of errors [40]. Therefore, like for computation of the vibrational spectra, HF does not seem to be appropriate to describe the geometry of pseudosaccharins. Indeed, the bond lengths obtained at the HF level of theory (with all basis set tested) are considerably shorter with respect to bond lengths calculated using the MP2 and DFT methods. As it could be expected, this is particularly noticeable for bonds involving the sulfur atom. Inclusion of polarization functions in the HF calculations resulted in further shortening of all bonds, markedly apparent for $\mathrm{C}-\mathrm{O}$ and $\mathrm{S}-\mathrm{X}$ bonds $(\mathrm{X}=\mathrm{C}, \mathrm{O}$ or $\mathrm{N})$. For example, the deviation of the $\mathrm{HF} / 6-311++\mathrm{G}(3 \mathrm{df}, 3 \mathrm{dp})$ calculated values from those obtained at the B3LYP/6-311++G(3df,3pd) level are within the range $0.023-0.043 \AA$, the latter value for the $\mathrm{S}-\mathrm{N}$ bond. The inability of HF to predict correctly the geometry of MBID is also clear if a comparison is made between the calculated results obtained at this level and available crystallographic data for other substituted arylpseudosaccharyl ethers. Although the overall value for the bond lengths in the $\mathrm{C}-\mathrm{O}-\mathrm{C}$ linkage for a series of arylpseudosaccharyl ethers is not as close as in the case of substituted aryltetrazolyl ethers $(2.777 \AA)$ [8], it is found in the quite narrow range of $2.752-2.802 \AA$ [13,16-19]. The HF predicts this values to fall between 2.716 and $2.728 \AA$, depending on the basis set applied, which is a clearly wrong prediction, even taking into account that the gas-phase and crystal data may differ somewhat. On the other hand, reasonable values for the $\mathrm{C}-\mathrm{O}-\mathrm{C}$ linkage, in the $2.762-2.783 \AA$ range, are obtained for all other levels of theory used.

In contrast to HF results, bond lengths resulting both from MP2 and B3LYP calculations with basis sets with restricted number of polarization functions are overestimated relatively to the $\mathrm{B} 3 \mathrm{LYP} / 6-311++\mathrm{G}(3 \mathrm{df}, 3 \mathrm{pd})$ reference data (see Table 3 ). In particular, quite distinctly different values for the $\mathrm{S}=\mathrm{O}$ and $\mathrm{S}-\mathrm{N}$ bond lengths are predicted by MP2 and B3LYP/6-311++G(3df,3pd). In this case, however, the reason of deviation might be ascribed to the basis set used rather than to the method itself, as a nearly coincidence is observed in the values obtained with both MP2 and B3LYP methods equipped with the same basis set $[\mathrm{MP} 2 / 6-31++\mathrm{G}(\mathrm{d}, \mathrm{p})$ vs. B3LYP/6-31++G(d,p) and $\mathrm{MP} 2 / 6-311++\mathrm{G}(\mathrm{d}, \mathrm{p})$ vs. B3LYP/6-311++G(d,p)].

The overestimation of the bond lengths does not depend only on the number of polarization functions present in the basis set. For example, the B3LYP/aug-cc-pVDZ basis set, which is comparable in this sense with the B3LYP/6$31++\mathrm{G}(\mathrm{d}, \mathrm{p})$ basis, predicts exceptionally long bonds (particularly evident for the $\mathrm{S}-\mathrm{N}$ and $\mathrm{S}=\mathrm{O}$ bonds), resulting in its deep inability to reproduce vibrational frequencies (refer to previous section). On the contrary, the computed bond lengths do not depend strongly on the additional splitting of the valence shell upon moving from the 6-31 type to the 6-311 type basis sets, which for the same method and 
Table 3

The chosen bond lengths for MBID optimized at different levels of theory

\begin{tabular}{|c|c|c|c|c|c|c|}
\hline \multirow[t]{2}{*}{ Method/basis set } & \multicolumn{6}{|c|}{ Bond length/A } \\
\hline & $\mathrm{C}_{1}-\mathrm{S}_{7}$ & $\mathrm{~S}_{7}-\mathrm{N}_{8}$ & $\mathrm{~S}_{7}=\mathrm{O}_{14} / \mathrm{S}_{7}=\mathrm{O}_{16}$ & $\mathrm{C}_{9}=\mathrm{N}_{8}$ & $\mathrm{C}_{9}-\mathrm{O}_{15}$ & $\mathrm{C}_{17}-\mathrm{O}_{15}$ \\
\hline $\mathrm{HF} / 6-31++\mathrm{G}(\mathrm{d}, \mathrm{p})$ & 1.779 & 1.660 & 1.427 & 1.270 & 1.300 & 1.428 \\
\hline $\mathrm{HF} / 6-311++\mathrm{G}(\mathrm{d}, \mathrm{p})$ & 1.779 & 1.656 & 1.419 & 1.266 & 1.297 & 1.426 \\
\hline $\mathrm{HF} / 6-311++\mathrm{G}(3 \mathrm{df}, 3 \mathrm{pd})$ & 1.768 & 1.636 & 1.401 & 1.264 & 1.294 & 1.422 \\
\hline B3LYP/aug-cc-pVDZ & 1.817 & 1.734 & 1.483 & 1.293 & 1.329 & 1.447 \\
\hline B3LYP/aug-cc-pVTZ & 1.802 & 1.699 & 1.449 & 1.284 & 1.323 & 1.443 \\
\hline B3LYP/6-31++G(d,p) & 1.809 & 1.715 & 1.464 & 1.292 & 1.327 & 1.447 \\
\hline B3LYP/6-31++G(3df,3pd) & 1.790 & 1.680 & 1.437 & 1.289 & 1.323 & 1.444 \\
\hline B3LYP/6-311++G(d,p) & 1.810 & 1.714 & 1.456 & 1.287 & 1.324 & 1.446 \\
\hline B3LYP/6-311++G(2df,2pd) & 1.797 & 1.689 & 1.441 & 1.284 & 1.321 & 1.442 \\
\hline B3LYP/6-311++G(3df,3pd) & 1.791 & 1.679 & 1.434 & 1.284 & 1.320 & 1.442 \\
\hline $\mathrm{MP} 2 / 6-31++\mathrm{G}(\mathrm{d}, \mathrm{p})$ & 1.791 & 1.715 & 1.464 & 1.298 & 1.333 & 1.450 \\
\hline MP2/6-311++G(d,p) & 1.789 & 1.710 & 1.449 & 1.294 & 1.326 & 1.443 \\
\hline
\end{tabular}

set of polarization functions produced practically coincident results.

The typical geometry for substituted pseudosaccharyl ethers is predicted by the calculations to be preserved in MBID. As mentioned in the Section 1, the very characteristic feature of this group of compounds is its uncommon $\mathrm{C}_{\mathrm{R}}-\mathrm{O}-\mathrm{C}_{\mathrm{A}}$ linkage (where $\mathrm{R}=$ heteroaromatic ring and $\mathrm{A}=$ allyl, benzyl, naphtyl or aryl group), which contains a short $\mathrm{C}_{\mathrm{R}}-\mathrm{O}$ bond $(1.311-1.335 \AA)$ and a much longer (1.417-1.488 $\AA$ ) $\mathrm{C}_{\mathrm{A}}-\mathrm{O}$ bond, together with a large $\mathrm{C}-\mathrm{O}-\mathrm{C}$ angle $\left(115.9-118.7^{\circ}\right)$ that indicates a nearly $\mathrm{sp}^{2}$ hybridization of the oxygen atom $[9,10,13,16-19]$. The observed features are a result of the strong electronegativity of the pseudosaccharyl group, quantitatively close to that of the fluorine atom [8]. The B3LYP/6$311++\mathrm{G}(3 \mathrm{df}, 3 \mathrm{pd})$ predicted $\mathrm{C}_{\mathrm{R}}-\mathrm{O}$ and $\mathrm{C}_{\mathrm{A}}-\mathrm{O}$ bond lengths in MBID are equal to 1.320 and $1.442 \AA$, respectively, well within the expected value ranges, whereas the calculated $\mathrm{C}_{\mathrm{R}}-\mathrm{O}-\mathrm{C}_{\mathrm{A}}$ angle of $117.0^{\circ}$ is in agreement with the suggested close to $\mathrm{sp}^{2}$ hybridization of the oxygen ether atom.

\section{Conclusions}

Quantum-chemical methods have been applied to model the geometry and the infrared spectra of MBID, a simple substituted pseudosaccharyl ether. The calculations were done at different levels of theory, employing both ab initio (HF, MP2) and DFT (B3LYP) methods combined with different basis sets $[6-31++G(d, p), 6-31++G(3 d f, 3 p d), 6-$ $311++G(d, p), 6-311++G(2 d f, 2 p d), 6-311++G(3 d f, 3 p d)$, aug-cc-pVDZ and aug-cc-pVTZ]. The results of the calculations were evaluated based on their relative capability to predict correctly the IR spectra of monomeric MBID obtained in low-temperature argon and krypton matrices.

An extensive set of polarization functions is necessary to correctly reproduce both the geometry and frequencies of the hypervalent $\mathrm{S}=\mathrm{O}$ bonds. However, the proper choice of the method and basis set is also crucial in order to obtain a good general agreement with the experimental data, i.e.,
B3LYP can only be said to reproduce the experimental spectra better than HF if the whole frequency range is taken into consideration, because accidental cancellation of errors lead to an excellent agreement between the experimental $v \mathrm{~S}=\mathrm{O}$ stretching frequencies and the corresponding HF calculated data. Very interestingly, it was found that Pople's type basis sets perform much better than Dunning's correlation consistent basis sets having the same number of polarization functions to calculate the geometry and infrared spectrum of the studied pseudosaccharin. On the whole, the B3LYP/6-311++G(3df,3pd) calculations give the best overall agreement between theoretically predicted and observed spectral and geometrical features, and then, among the different alternatives tested, appear as the most convenient theoretical approach to the study of the type of compounds under consideration.

Finally, the latter level of theory was applied to analyze the vibrational spectra and the geometry of MBID. In agreement with the experiment, the $\mathrm{C}-\mathrm{O}-\mathrm{C}$ linkage in MBID is predicted by these calculations to exhibit considerably short $(1.320 \AA)$ and long $(1.442 \AA)(\mathrm{N}=) \mathrm{C}-\mathrm{O}$ and $\left(\mathrm{H}_{3}\right) \mathrm{C}-\mathrm{O}$ bonds, respectively, and a hybridization of the central oxygen atom close to $\mathrm{sp}^{2}$ (the $\mathrm{C}-\mathrm{O}-\mathrm{C}$ angle is predicted to be $c a .117^{\circ}$ ). This $\mathrm{C}-\mathrm{O}-\mathrm{C}$ bonding pattern fits the well-known high reactivity of MBID upon thermal rearrangement, which has been shown to result in easy selective $\left[1,3^{\prime}\right]$-isomerization of the compound.

\section{Acknowledgements}

Calculations were partially done at the Academic Computer Center "Cyfronet", Krakow, Poland (Grant KBN/ SGI_ORIGIN_2000/UJ/044/1999), which is acknowledged for computing time. The research was supported by the Portuguese Fundação para a Ciência e a Tecnologia (Grant FCT \#SFRH/BPD/17081/2004 and projects POCI/QUI/ 59019/2004 and POCI/QUI/58937/2004). AGZ is member of the research career Conicet (National Research Council, Argentina). 


\section{Appendix A. Supplementary data}

Supplementary data associated with this article can be found, in the online version, at doi:10.1016/ j.molstruc.2007.06.004.

\section{References}

[1] E.B. Wilson, Phys. Rev. 45 (1934) 706.

[2] M. Otten, W. von Deyn, S. Engel, R.L. Hill, U. Kardorff, M. Vossen, P. Plath, H. Walter, EP0961774, (1999).

[3] F. Zani, M.R. Mingiardi, C.A. Maggiali, P. Mazza, Farmaco 51 (1996) 707.

[4] M. Mor, F. Zani, P. Mazza, C. Silva, F. Bordi, G. Morini, P.V. Plazzi, Farmaco 51 (1996) 493.

[5] F. Zani, P. Vicini, Arch. Pharm. 331 (1998) 219.

[6] P.I. Eacho, P.S. Foxworthy-Mason, H.-S. Lin, J.E. Lopez, M.K. Mosior, M.E. Richett, EP1274708, (2006).

[7] A.F. Brigas, R.A.W. Johnstone, Tetrahedron Lett. 31 (1990) 5789.

[8] J.A.C. Alves, J.V. Barkley, A.F. Brigas, R.A.W. Johnstone, J. Chem. Soc. Perkin Trans. 2 (1997) 669.

[9] N.C.P. Araujo, A.F. Brigas, M.L.S. Cristiano, L.M.T. Frija, E.M.O Guimaraes, R.M.S. Loureiro, J. Mol. Catal. A - Chem. 215 (2004) 113.

[10] L.M.T. Frija, M.L.S. Cristiano, E.M.O. Guimaraes, N.C. Martins, R.M.S. Loureiro, J.F. Bickley, J. Mol. Catal. A - Chem. 242 (2005) 241.

[11] B.J. Hussey, R.A.W. Johnstone, I.D. Entwistle, Tetrahedron 38 (1982) 3775 .

[12] A.F. Brigas, R.A.W. Johnstone, J. Chem. Soc. Chem. Commun. (1994) 1923.

[13] J.V. Barkley, M.L.S. Cristiano, R.A.W. Johnstone, R.M.S. Loureiro, Acta Crystallogr. C - Cryst. Struct. Commun. 53 (1997) 383.

[14] S. Brodersen, A. Langseth, Mat. Fys. Skr. Dan. Vid. Selsk 1 (1956).

[15] A.F. Brigas, R.A.W. Johnstone, J. Chem. Soc. Perkin Trans. 111 (2000) 1735

[16] J.A.C. Alves, A.F. Brigas, R.A.W. Johnstone, Acta Crystallogr. C Cryst. Struct. Commun. 52 (1996) 1576.

[17] A.F. Brigas, P.M. Goncalves, R.A.W. Johnstone, Acta Crystallogr. C - Cryst. Struct. Commun. 54 (1998) 251.

[18] A.F. Brigas, R.A.W. Johnstone, Acta Crystallogr. C - Cryst. Struct. Commun. 52 (1996) 1293.

[19] N.C.P. Araujo, P.M.M. Barroca, J.F. Bickley, A.F. Brigas, M.L.S Cristiano, R.A.W. Johnstone, R.M.S. Loureiro, P.C.A. Pena, J. Chem. Soc. Perkin Trans. 2 (2002) 1213.

[20] M.A.R. Matos, M.S. Miranda, V.M.F. Morais, J.F. Liebman, Mol. Phys. 103 (2005) 221.

[21] M. Remko, J. Phys. Chem. A 107 (2003) 720.

[22] I.G. Binev, B.A. Stamboliyska, E.A. Velcheva, Spectrochim. Acta, Part A - Mol. Biomol. Spectrosc. 52 (1996) 1135.

[23] Y.I. Binev, C.T. Petkov, L. Pejov, Spectrochim. Acta, Part A - Mol. Biomol. Spectrosc. 56 (2000) 1949.

[24] P. Naumov, G. Jovanovski, Struct. Chem. 11 (2000) 19.
[25] G. Jovanovski, S. Tanceva, B. Soptrajanov, Spectrosc. Lett. 28 (1995) 1095.

[26] A. Borba, A. Gomez-Zavaglia, P. Simoes, R. Fausto, Spectrochim. Acta, Part A - Mol. Biomol. Spectrosc. 61 (2005) 1461.

[27] A. Borba, A. Gomes-Zavaglia, P. Simoes, R. Fausto, J. Phys. Chem. A 109 (2005) 3578

[28] A.H. Zeng, L. Yu, Y. Wang, Q.Y. Kong, Q. Xu, M.F. Zhou, J. Phys. Chem. A 108 (2004) 6656.

[29] A. Kaczor, T. Melo, M.I.L. Soares, R. Fausto, J. Phys. Chem. A 110 (2006) 6531.

[30] A.D. Becke, Phys. Rev. A 38 (1988) 3098.

[31] C.T. Lee, W.T. Yang, R.G. Parr, Phys. Rev. B 37 (1988) 785.

[32] P. Csaszar, P. Pulay, J. Mol. Struct. 114 (1984) 31.

[33] O. Farkas, H.B. Schlegel, J. Chem. Phys. 111 (1999) 10806.

[34] M.J. Frisch, G.W. Trucks, H.B. Schlegel, G.E. Scuseria, M.A. Robb, J.R. Cheeseman, V.G. Zakrzewski, J.A. Montgomery, Jr., R.E. Stratmann, J.C. Burant, S. Dapprich, J.M. Millam, A.D. Daniels, K.N. Kudin, M.C. Strain, O. Farkas, J. Tomasi, V. Barone, M. Cossi, R. Cammi, B. Mennucci, C. Pomelli, C. Adamo, S. Clifford, J.W. Ochterski, G.A. Petersson, P.Y. Ayala, Q. Cui, K. Morokuma, P. Salvador, J.J. Dannenberg, D.K. Malick, A.D. Rabuck, K. Raghavachari, J.B. Foresman, J. Cioslowski, J.V. Ortiz, A.G. Baboul, B.B. Stefanov, G. Liu, A. Liashenko, P. Piskorz, I. Komaromi, R. Gomperts, R.L. Martin, D.J. Fox, T. Keith, M.A. Al-Laham, C.Y. Peng, A. Nanayakkara, M. Challacombe, P.M.W. Gill, B. Johnson, W. Chen, M.W. Wong, J.L. Andres, C. Gonzalez, M. Head-Gordon, E.S. Replogle, J.A. Pople, GAUSSIAN 98, Revision B.01. In Gaussian, Inc., Pittsburgh, PA, 2001.

[35] M.J. Frisch, G.W. Trucks, H.B. Schlegel, G.E. Scuseria, M.A. Robb, J.R. Cheeseman, J.A. Montgomery, Jr., T. Vreven, K.N. Kudin, J.C. Burant, J.M. Millam, S.S. Iyengar, J. Tomasi, V. Barone, B. Mennucci, M. Cossi, G. Scalmani, N. Rega, G.A. Petersson, H. Nakatsuji, M. Hada, M. Ehara, K. Toyota, R. Fukuda, J. Hasegawa, M. Ishida, T. Nakajima, Y. Honda, O. Kitao, H. Nakai, M. Klene, X. Li, J.E. Knox, H.P. Hratchian, J.B. Cross, V. Bakken, C. Adamo, J. Jaramillo, R. Gomperts, R.E. Stratmann, O. Yazyev, A.J. Austin, R. Cammi, C. Pomelli, J.W. Ochterski, P.Y. Ayala, K. Morokuma, G.A. Voth, P. Salvador, J.J. Dannenberg, V.G. Zakrzewski, S. Dapprich, A.D. Daniels, M.C. Strain, O. Farkas, D.K. Malick, A.D. Rabuck, K. Raghavachari, J.B. Foresman, J.V. Ortiz, Q. Cui, A.G. Baboul, S. Clifford, J. Cioslowski, B.B. Stefanov, G. Liu, A. Liashenko, P. Piskorz, I. Komaromi, R.L. Martin, D.J. Fox, T. Keith, M.A. AlLaham, C.Y. Peng, A. Nanayakkara, M. Challacombe, P.M.W. Gill, B. Johnson, W. Chen, M.W. Wong, C. Gonzalez, J.A. Pople, GAUSSIAN 03, Revision C.02. In Gaussian, Inc., Wallingford, CT, 2004.

[36] P. Pulay, G. Fogarasi, F. Pang, J.E. Boggs, J. Am. Chem. Soc. 101 (1979) 2550.

[37] J.M.L. Martin, C. Van Alsenoy, GAR2PED, In University of Antwerp, 1995

[38] V. Typke, M. Dakkouri, J. Mol. Struct. 599 (2001) 177.

[39] V. Jonas, G. Frenking, Chem. Phys. Lett. 177 (1991) 175.

[40] D. Vijay, U.D. Priyakumar, G.N. Sastry, Chem. Phys. Lett. 383 (2004) 192. 